\title{
Gender Specific Activities And Its Relationship With The Self Concept Of Adolescents
}

\author{
Nazia Iqbal \\ Department of Psychology \\ International Islamic University \\ Nighat Gillani \\ \& \\ Anila Kamal \\ National Institute of Psychology \\ Quaid-i-Azam University
}

\begin{abstract}
The research was designed to study the Gender related activities i.e. those activities which are stereotypically related to girls and boys and their relationship with the self concept of adolescents. The data was collected from a sample of Adolescents girls and boys between age ranging from (16-20) years belonging to same family. Total number of families included for the data collection was 50. (i.e. Adolescents =100) An Activity Scale by Terry Honess (1994) was used to see what kind of activities girls and boys are allowed/ accepted to perform. The activity scale had three types of activities, activities and tasks that are considered as male oriented, secondly female oriented and those which are neutral (both male and female are accepted to perform). In order to measure self concept of male and female adolescents the self concept scale (Urdu Adjective Checklist UACL; Ansari et.al. 1982) was used. Results indicated that boys and girls perform gender specific activities. The self concept of girls was significantly low on self concept scale as compared to the boys. Out of nine dimensions of the self concept scale Adolescents' boys score significantly high on Aggression, Autonomy, Affiliation and Dominance. On the other hand females scored higher on Succorance and Abasement dimensions. These findings show cultural stereotypes in different walks of life. It also reveals that the self concept has a strong relationship with the freedom of movement and expression of young boys and girls. Results are discussed and conclusions are drawn keeping in perspective the cultural expectations and stereo types and its impact on the self concept of young boys and girls.
\end{abstract}

Key Word: Gender Activities, Self, Adolescence

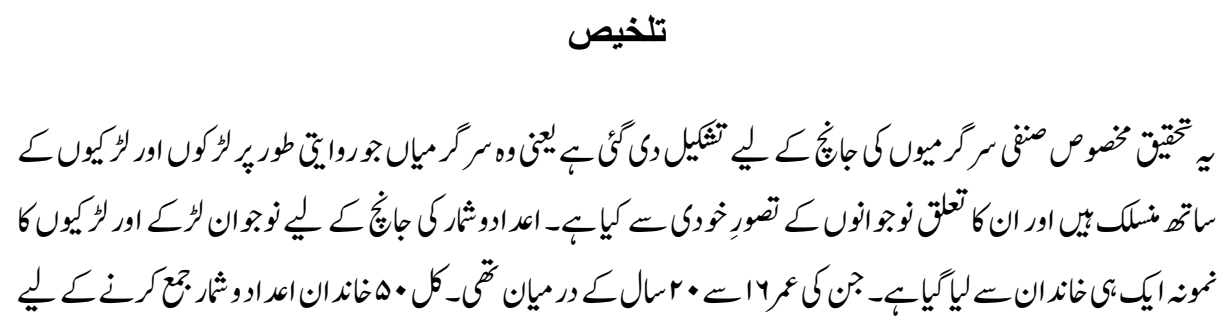




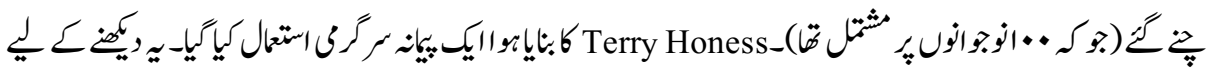

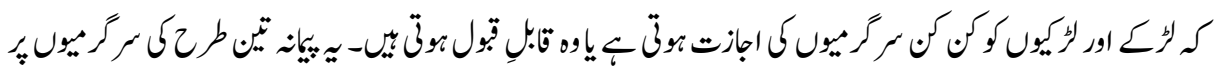

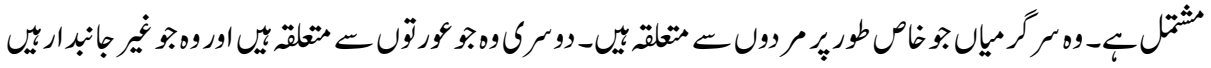

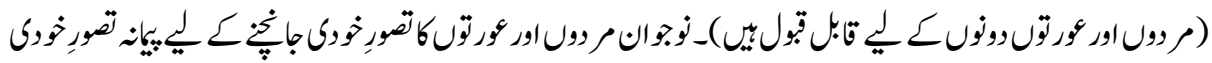

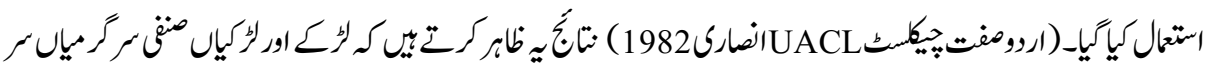

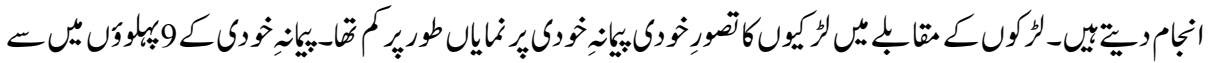

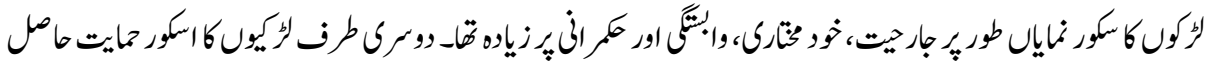

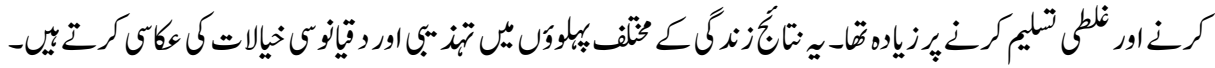

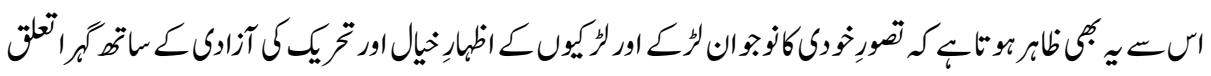

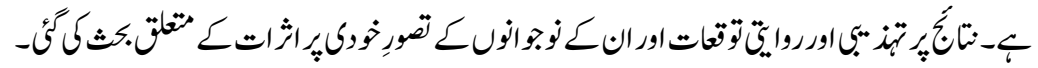

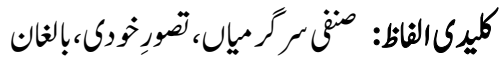

\section{Introduction}

Adolescence is the period in human development that occurs between the beginning of puberty and adulthood. The word "adolescence" comes from the Latin adolescere meaning "to grow into maturity". Not only it is a time of enormous physiological change, adolescence is also marked by changes in behavior and expectations.

The main idea behind this study was to investigate the gender differences in terms of the activities that they perform and its relationship with the self-concept of adolescence. Due to the patriarchal standers of our society most parents up bring their sons and daughters differently (Lorber, 1994). Literature review suggested that there is a definite prevalence of gender roles in our society. Generally it is divided in to two broad categories early adolescence (12-16), late adolescence (17-20). The era of Adolescence is called a process for attaining position and beliefs needed for successful participation in society (Rogers, 1977).

Hall (as cited in Lefrancoise, 1981) viewed adolescence "as a period of second birth" Involving dramatic storm and stress. During that period of adolescence experience great changes in their self-concept and self-esteem. While there are generalized patterns of adolescent growth, there are also individual influences that affect the development of self-concept and self-esteem. Autonomy is a status symbol for the adolescence. It tells his peers that he is no longer a child but has been granted the status of a near adult. Autonomy is also significant personally because the adolescent uses it to measure his 
adequacy to handle his own affair. Adolescents question the need for some parental control or punishment when they intentionally go against family rules, they do offer question the kind of control they are subjected to.

Sex is a biological term but gender is a psychological term and gender illustrates the roles of women and man that is established by political, economic, social and cultural aspects rather than by biology. People are born with the characteristics of female or male and then learn to be women and men. There are some set behaviors, attitudes, roles and expectations that is learned behavior that forms gender identity and determines gender roles. Gender roles are joint prospect that apply to individuals on the basis of their socially acknowledged sex. So at the embedded or open level, most people cling to the excepted behaviors which are suitable for men or for women. Literature gives labels to gender role that is communal and agnatic. Women are thought to behave in communal manner which is represented as friendly, unselfish, concerned with others, and emotionally expressive. Men are thought to behave in a manner that can be describe as agnatic which means independent, domineering nature and self-confident. According to Rober (cited in Fagot, 1997) sex role is the full complement of behavior and attitude as associated with ones physical sex. Generally gender roles are not exactly the same across the world. Gender roles involve set of rights and duties which is expected from an individual and appreciated if he/she performed according to the norms. A lot of religious and cultural factors alter and regulate the roles of men and women in different societies. But there are a lot of prevailing influences especially by male members of the society. The important dimensions are power and sexuality.

\section{Theories and Models of Gender Roles}

There are many theories which explains the gender role behavior (Jackline, 1989)

- Psychoanalytic Theory (Parental Identification Theory) Gender roles are learnt as the results of a socialization process in which the child identify with the parent of the same sex. Those roles are considered the natural and normal outcome of biology different between males and females (Pervez, 1996). Parental identification is the process by which the child adopts and internalized parental value, attitudes, behavioral traits, and personality characteristics.

- Cognitive development theory. The cognitive development theory suggests that gender is cognitively assigned to the child at birth and that is subsequently acknowledged by him or her while rising up in a certain culture. A child's ability to understand of the world is dependent upon his/her aptitude to draw conclusion, process information, and logical reasoning. Kohlberg (1973), the chief advocate of this view, highlighted that the child own self categorization either by a boy or a girl is the fundamental planner of sex-role position and mind-set that develop. Sex differentiation take place gradually as children learn to be male or female according 
to culturally established sex-role expectations.

- Social learning theory. The gender typed behaviors are learned similarly as the child learns other behaviors. In social learning approach rewards and punishment are the basic tools for learning any behaviors. Observational learning through modeling is also a very effective. A child as a passive recipient of culturally passes on information. For example girls are rewarded for certain category of behaviors and punished for other type of behaviors and these are not the same for boys.

- Gender schema theory. There are different believes which are given to children through the socialization process. Specific believes are internalized by children and become a part of their socialization into adult roles. As children grow older they have more familiarity about gender roles and are more likely to make inferences about gender behavior and attitudes based on little information (Golombok \& Fivush, as cited on Fernandez, 2001).

The second variable in the study is the self concept and which is the whole set of attitudes, opinions, and cognations that a person has of himself. It is the core of the personality patterns which provides its unity, is the "self". Rogers (1961) defines selfconcept as an organized configuration of perceptions of the self which are admissible to one's consciousness of one's characteristics and abilities. According to Carl Jung (1933) the "self' is always striving for oneness and harmony. Struggling for the harmony and completeness of oneself is the eventual aim of life. According to Marsh and Jackson self concept is very important phenomenon but literature provides very little information and a few theoretical models available for its explanation. Similarly, the construct was measured by a very low quality tools e.g. questionnaires or interview guidelines (as cited in Hodge 1994). In an effort to solve this problem, researchers come to the conclusion for the multidimensionality of self-concept which emphasizes that people have different kinds of self concepts ranging from work, physical and social self concept. (Harter et al., as cited in Asci, 2002).

Self is something which has a development, it is not initially there at birth but arise in the process of social experiences and activity, that is develops in the given individual as a result of this relation to that process. Developing a self-concept is a significant task in early childhood the baby has to recognize and realize that he is a separate being. Looking at a baby's perception of himself in a mirror can best show this. At school age children start seeing themselves as having unique and significant personal qualities. They gain a strong sense of their gender roles. Long before the child reaches adolescence he builds up a concept of his own role in the family as well as impressions of the roles of other family members. Parents and siblings likewise have concepts of the roles various family members should play.

The self-concept is always having an emotional nature because we cannot be unconcerned to ourselves. Additionally our self-concept is positive "we feel attractive 
and handsome", we like who we are, our social identity is well-built; and then self concept is high. On the contrary, when our self-concept is negative we don't like ourselves, we have a fragile identity. In these circumstances, the person comes across lack of self-reliance and lack of self-confidence that any situation generates anxiety.

In reviewing the research on gender and self-concept, Stake (as cited in Hodge 1994) noted that gender differentiation in self-concept are generally reliable with gender stereotypes and with the different socialization practices. Thus, girls and women tend to rate themselves higher on self-concept scales that send forth the capability to establish and maintain balance relationships with others, and on measures that reflect moral goodness and virtue. Male tend to rate themselves higher on dimensions that are more towards dominance and leader like characteristics. Andrew (as cited in Hodge 1994) also find results consistent with gender stereotypes, women express more self-assurance about verbal tasks, whereas men express more self-belief about mathematical tasks.

Bems theory (1974) expected that gender schematic persons choose gender related activities that are consistent with their self-concepts, because of their impetus to verify to gender role principles. In our social context despite of cultural acceptations denying others expectations about male or female behavior can bring a variety of negative reactions, whereas behaving according to the expectations can bring rewards of Social approval and collaboration.

Green, Hebron, and Woodward (1990) establish that females from their childhood had more restrictions for their leisure activities especially activities outside the home as compared to the young males who are more open and permitted to go out freely. Adolescent females have significantly lower self esteem and significantly higher amounts of intrapersonal and total constraints than males" which makes them less likely to participate in many leisure activities (Raymore, Godbey, \& Crawford, 1994).

Parents support their sons and daughters to take part in sex-typed activities, for example doll playing and engaging in housekeeping activities for girls and playing with trucks and engaging in sports activities for boys (Eccles, Jacobs, \& Harold, 1990). Children's toy preferences have been found to be significantly related to parental sex typing, in with parents providing gender-differentiated toys and rewarding play behavior that is gender stereotyped (Carter, 2000). Mothers and fathers both add to the gender stereotyping of their children, fathers have been found to reinforce gender stereotypes more often than mothers (Ruble, 1988).

Parents' decisions and guidance on how adolescents spend their free time, and the Importance placed on completing homework, indicate the level of family ruling. These factors have been shown to affect educational outcomes. To examine this type of parental 
involvement, three measures of parental supervision were used: checking homework, limiting television watching, limiting going out with friends. Research has shown that parents supervise daughters more closely than they do sons (Block \& Muller, as cited in Weitz 1977). This fit the idea that females are socialized to be dependent, submissive and obedient, while males are socialized to be independent and self-willed.

No research evidence has been formed in Pakistani Cultural context in relation to gender specific activities and self-concept of boys and girls. So it was considered important to identify the relationship between the two. Activities are gender specific and those related to the use of cognitive functioning, confidence and mathematical tasks and tasks presented in an achievement context, are mostly assigned to males where as tasks, that involves house hold chores: verbal tasks and mental work are usually assigned to female (Marsh as cited in Hodge, 1994). In present research we are interested in finding out the activities boys and girls are assigned to perform and its relationship with their self-concept. This study would stimulate further research in this area and would provide grounds for other researcher interested in studying gender differences in different aspects of life. It is a small effort to understand these dimensions and help to create awareness in this regard.

The following hypotheses have been formulated for the present research:

1. Male adolescence will be allowed /expected to perform more male oriented activities compare to the female adolescents and vice versa.

2. Self-concept of male adolescents will be higher than female adolescents.

3. Gender specific activities will have positive relationship with self-concept.

\section{Sample}

A total of 100 adolescents were contacted from two colleges including both government and semi-government institutions of Islamabad. The data was collected from those families only that had both male and female teenage children. Two siblings from each family i.e. (a brother and a sister) were taken. The sample consisted of 50 female and 50 male adolescents. The age range of sample was from 16-20 years. The mean age of respondents was 17.91 years.

\section{Instruments}

\section{The Activity Scale}

Part 1 of the present research was about the translation of the Activity scale. This scale was developed by Terry Honess (1994). The scale was in English and was translated by the permission of the author into Urdu. The sample for translation consisted of three teachers and four M.Phil and two Ph. D scholars who had command on both the languages i.e. Urdu and English. They were approached individually and were instructed 
to translate each and every item as accurately as they could so that it conveys the exact meaning of the original given item. The actual scale consisted of 24 items. To make the scale culturally appropriate two items were discarded from it and six more items were added in the scale that seemed relevant to our culture. This was done with the permission of the author. It is a Likert type questionnaire with 4-point response format, so finally the scale consisted of 28 items. This scale basically measures three dimensions i.e. male specific activities, female specific activities and neutral activities (i.e. performed by male and female both). Items $1,4,5,6,7,13,25,26$, measure female specific activities; items $12,14,16,18,19,20,21,22,23,27$ measure the male specific activities, and items 2, 3, $8,9,10,11,15,17,24,28$ is related to neutral activities. The response categories ranked from very often (4), some times (3), occasionally (2) and not at all (1). The maximum score on this scale was 112 and minimum was 28 .

\section{Self-Concept Scale}

The second scale Urdu adjective checklist (UACL), also called self-concept scale was developed by Ansari et.al. in 1982. That scale consists of popular adjectives in Urdu language, which was easily understood by the general population of Pakistan. The final version of that scale consists of 54 adjectives both negative and positive. The respondents had to rate each item on one to five categories ranging from most to least. The maximum score on this scale was 270 and minimum score was of 54.

There were nine sub-scales in self-concept scale of which each subscale consisted of different number of adjectives.

1. Succorance self-concept scale (6 Adjectives)

2. Aggression self-concept scale (11 Adjectives)

3. Achievement self-concept scale (10 Adjectives)

4. Autonomy self-concept scale (7 Adjectives)

5. Affiliation self-concept scale (9 Adjectives)

6. Nurturance self-concept scale (12 Adjectives)

7. Intelligence self-concept scale (12 Adjectives)

8. Dominance self-concept scale (8 Adjectives)

9. Abasement self-concept scale (6 Adjectives)

These subscales are used by keeping in perspective the following definitions given in the manual:

1. Succorance: This refers to have the needs gratified by the sympathetic aid of an allied object. To be nursed, supported, sustained, surrounded, protected, loved, advised, guided, indulged, forgiven, and consoled.

2. Aggression: This refers to overcome opposition forcefully, to fight, attack, injure or kill another person; to oppose forcefully and to revenge an injury.

3. Achievement: This refers to accomplish something difficult, to master, manipulate 
or organized physical objects, human beings or ideas, to overcome obstacles and attain a high standard.

4. Autonomy: This refers to be mature, stable, calm, phlegmatic, free to move and make own decisions.

5. Affiliation: This refers to draw near and enjoyably cooperate or reciprocate with an allied other. To please and win affection of a catheter object and to adhere and remain loyal to a friend.

6. Nurturance: This refers to give sympathy and gratify the needs of a helpless object, an infant or any object that is week, disabled, tired, inexperienced, defeated, humiliated, lonely, objected, sick or mentally confused.

7. Intelligence: This refers to be bright, conscientious persevering intellectual and cultured, tackle the situation according to a given situation.

8. Dominance: This refers to control one's human environment. To influence or direct the behavior of others by suggestions, persuasion and command. To dissuade, restrain or prohibit. To be assertive, self assured, independent minded, hard, stem, solemn, unconventional, and tough.

9. Abasement: This refers to submit passively to external force. To accept injury, blame, criticism, punishment. To surrender, to become resigned to fate, admit inferiority, error, wrong doing, or defeat. To confess, mutilate the self. Seek and enjoy pain, punishment, illness and misfortune.

\section{Procedure}

Before the main study a pilot study was conducted on 20 boys and 20 girls belonging to the same family. The purpose of the pilot study was to determine the cultural relevance and comprehensibility of the items used in the scales for adolescents. After the assurance of the cultural adaptability the scales were used for the final study.

After taking permission from the principals of the two colleges i.e. Federal Government College for women F-7/2 Islamabad and Islamabad College for boys' F-8/4, both the scales were administered to 250 adolescents. The adolescents were approached in their classes then were briefed about the nature of the research. First they were asked if they have a sibling between the age ranges of 16-20 years. Those who fulfilled the criterion were taken out from the class and scales were given to them in another room. They were also given the same scales for their siblings to fill. They were told that the researcher would come back to their college after two days to collect the filled questionnaire of their siblings.

All of them were requested to answer as honestly and accurately as they could and not to leave any question unanswered. After two days the siblings' questionnaires were collected from them and they were thanked for their participation. In this process many questionnaires were not returned or unfilled by any of the sibling so in the end a total of 100 adolescences were used in analysis. 


\section{Results}

The following results are obtained through the Activity scale with 28 items and possible score range from 28 to 112 and the second scale is the self concept scale with the possible score range from 54 to 270 .

The Alpha reliabilities of the Activity scale is .77and that of Self concept scale is .73 which shows that both scale are the reliable measures of the above mentioned concept. The Alpha reliabilities of the 10 items Male oriented activities subscale is 0.64 , The Alpha reliabilities of the 8 items female oriented activities subscale is 0.82 , The Alpha reliabilities of the 10 items of neutral activities subscale is 0.58 .

Table: 1

Mean, standard deviation and $t$-value of boys and girls on The Self concept scale $(\mathrm{N}=\mathbf{1 0 0})$

\begin{tabular}{|l|c|c|c|c|c|}
\hline Groups & $\mathbf{N}$ & $\mathbf{M}$ & SD & t & P \\
\hline Boys & 50 & 275.1 & 22.1 & & \\
\hline & & & & 3.1 & .007 \\
\hline Girls & 50 & 262.7 & 17.6 & & \\
\hline
\end{tabular}

$d f=98$

Table 1 shows that the differences between the male and female on self concept scale are significant $(\mathrm{t}=3.1, d f=98)$.this table shows that there is much differences in the two groups in their self concept. These findings implies that male have higher self concept than female.

Table: 2

Mean, standard deviation and t-value of Boys and Girls on The Sub-Scale of the self concept scale $(\mathrm{N}=100)$

\begin{tabular}{|c|c|c|c|c|c|}
\hline Sub-Scales & \multicolumn{2}{|c|}{ Boys $(n=50)$} & \multicolumn{2}{|c|}{ Girls $(n=50)$} & \\
\hline & $\mathbf{M}$ & SD & $\mathbf{M}$ & SD & $\mathbf{t}$ \\
\hline Succorance & 16.9 & 3.4 & 20.1 & 2.9 & $4.99 * *$ \\
\hline Aggression & 34.1 & 6.3 & 30.5 & 4.9 & $3.11 * *$ \\
\hline Achievement & 37.6 & 6.3 & 35.9 & 7.2 & 1.23 \\
\hline Autonomy & 25.9 & 3.9 & 22.4 & 4.6 & $4.12 * *$ \\
\hline Affiliation & 31.7 & 4.4 & 28.9 & 2.8 & $3.77 * *$ \\
\hline Nurturance & 40.3 & 5.4 & 38.7 & 3.4 & 1.69 \\
\hline Intelligence & 43.4 & 5.6 & 42.4 & 5.8 & 0.83 \\
\hline Dominance & 28.8 & 4.4 & 25.1 & 5.6 & $3.70 * *$ \\
\hline Abasement & 16.4 & 2.9 & 18.7 & 3.5 & $3.47 * *$ \\
\hline
\end{tabular}

$d f=98, * p<.05, * * p<.01$. 
The results shown in table 2 show that there is significant differences in boys and girls in six subscales of self concept scale.

Table: 3

Mean, standard deviation and t-value of husbands and wives on The Disagreement Scale $(\mathbf{N}=260)$

\begin{tabular}{|l|c|c|c|c|c|}
\hline $\begin{array}{l}\text { Sub-scales of The } \\
\text { Activity scale }\end{array}$ & \multicolumn{2}{|c|}{$\begin{array}{c}\text { Boys } \\
(\mathbf{n = 5 0})\end{array}$} & \multicolumn{2}{c|}{$\begin{array}{c}\text { Girls } \\
(\mathbf{n = 5 0})\end{array}$} & \\
\hline & M & SD & M & SD & t \\
\hline Male Oriented & 26.56 & 4.81 & 22.42 & 4.57 & $4.41^{* *}$ \\
\hline Activities & & & & & \\
\hline Female Oriented & 15.48 & 5.41 & 22.14 & 4.84 & $6.48^{* *}$ \\
\hline Activities & & & & & \\
\hline Neutral Activities & 28.1 & 5.17 & 27.44 & 4.53 & .552 \\
\hline
\end{tabular}

$d f=98, * p<.05, * * p<.01$.

Table three shows that there are significant differences in two groups in terms of their activities, which imply that girls perform less number of male oriented activities then boys. On the other hand boys perform less number of female oriented activities then girls. These findings further elaborated the fact that there are non-significant differences in Boys and Girls on neutral Activities, which implies that boys and Girls had similar scores on neutral activities.

\section{Discussion}

In the present study a comparative picture of gender participation in various every day activities and its relationship with their self-concept is presented. The results on the activity scales indicated gender differences in terms of the activities that boys and girls are allowed or expected to do. It shows that boys mostly performed the activities that are male oriented (e.g., allowed to have friends in house when parents are not at home, drive own car or bike and go to college and come back independently etc.). Boys scored higher on these activities compared to the girls $(p=.001)$ and scored low on the female oriented activities. On the other hand girls scored more on the female oriented activities (e.g., Clean own room, wash up dishes, help mother in the house hold chores, baby sit for younger brother or sister and make own bed etc). Girls scored low on male oriented activities. The difference between girls and boys was significant $(p=.001)$. There were also some neutral activities included in the scale that usually boys and girls both are allowed/expected to perform (e.g., Select own cloth for the day, participate in non academic activities, take telephone messages, decide what goes on in own room and decide own bed time etc.). On these types of activities there was non-significant 
difference between both groups. These results support the previous researches quoted earlier (e.g., Berns, 1974; Archer \& McDonald, 1990; Garton \& Pratt, 1998; Green, Hebron, \& Woodward, 1990; Raymore, Godbey, \& Crawford, 1994)

On the Self-Concept Scale it was noted that boys scored higher in four sub scales on which there is a significant difference between boys and girls and boys scored high on these scales. These are Aggression, Autonomy, Affiliation, and Dominance. On the other hand girls' scores are low on the above mention scales. Girls scored higher on the sub scales of Abasement and Succorance. There were no gender differences on the subscales of Intelligence, Achievement, and Nurturance. All these findings are supported by previous researches (Macooby and Jacklin, 1974). According to them, males scored higher on aggression, dominance, and self-confidence, whereas female scored high on verbal ability, compliance, nurturance and empathy scales. Similarly, Monge (as cited in Horrocks, 1976) found out that there is a difference between boys and girls in the content and development of self-view. He reported that boy's self-ratings were higher than girls in every grade of school; it also increased from grade (class) 6 to 12. Also on most of the factors boys rated themselves higher than girls showing their high self-concept.

The results indicated a clear gender difference not only on the activities that girls are allowed or expected to perform but also in terms of the self-concept compare to the boys. Boys had relatively higher self-concept. These results are an expression of our cultural values and social norms that emphasizes gender differences in different walks of life. The activities youngsters are allowed to perform in their daily lives had a different impact on the kind of personalities they develop. The identity development of youngsters is linked with the freedom of movement and expression. Boys are usually encouraged to be strong, aggressive, dominant and autonomous. Dependencies are considered a sign of weakness for boys. On the other hand, girls are encouraged to be nurturance, submissive and polite. The activities that strengthen these aspects of behaviors are encouraged among boys and girls. Female receives less encouragement and appreciation and have high need to be loved and protected. She seeks support from others. At this age of adolescence, boys learn from the society that how to behave like a male individual. It has been observed that males are more aggressive than females at a very early age (Bandura, as cited in Lefrancoise, 1981). Males tend to be more aggressive than females in most cultures; also non-human primates exhibit the same sex difference with respect to aggression (Mitchell, as cited in Lefrancoise, 1981).

When we looked at activities individually we found that there were some prominent differences in the activities of boys and girls, that is, on some activities, boys scored very high and on others girls scored very high. But interestingly the whole group of boys and girls scored very low on some activities (e.g. allowed to have friends at home when parents at home, spends night at friends home and prepare own breakfast etc). These low 
scores on particular activities suggested that boys and girls both do not perform certain activities frequently. The reason might be that there are certain tasks, which are not accepted and liked by the elders for their youngsters to perform. For example, sleeping over a friend's house is not considered safe or in line with the traditional family values. So boys are not allowed to sleep over a friend's house like girls. Similarly they scored equally low on the activity of making own breakfast. This could be an indication of the traditional activity that mothers perform. Making breakfast for their children is usually considered mothers duty so they do it for both boys and girls. Another activity in which both of them scored low is "allowed to have friends in house when parents are not at home". This again is related to social norms and values in which parents like to guard their children and protect them from possible danger in their absence. Kids are considered to be vulnerable, so they are not allowed to have strangers at home when their parents are not there to watch them.

The data was collected from same families having adolescents' boys' and girls' siblings, so that there is a consistency in the environment of both and also parental treatment for both brothers and sisters was from same parents. High score of girls on the activities scale reveals hat girls in our society have many responsibilities from very early age of life as compare to boys. They are supposed to be responsible for many household activities from the beginning of their teenage. Freedom of mobility is the basic right of every individual but the girls have restricted mobility. They are confined to perform only female oriented activities specifically, but not male oriented activities, including going for shopping alone, allowed to have friends in house when parents are not at home, decide for self how to spend leisure time, drive car or bike and go to school and come back independently.

It can be said that differential treatment and socialization play a very important role in adolescent activities. Boys and girls are brought up with different points of reference. A boy is allowed to go out, play and do what ever he wants to do; it enhances his selfconcept and flourishes his cognitive abilities. On the other hand girl child, from the same family brought up in suppressed environment. Girls from very beginning are taught to be good girls, never question to parents and be submissive etc. that definitely affect her cognitive schemas and they ultimately develop a lower self-concept. The reasons are socio-cultural, but it affects families in general and their treatment to their youngsters in particular.

\section{Conclusions}

The purpose of the present study was to examine some gender specific activities and its relationship with the self-concept of adolescents. As far as gender specific activities are concerned. Sample was comprised of 100 adolescents (brothers and sisters) from different colleges of Islamabad. 
Findings of the study show that activities are related to self-concept. There was difference in the activities that we are allowed/expected to perform have a relationship with self-concept. Differences in activities are there in terms of its nature and specification. On self-concept scale there is a significant gender difference and boys scored higher on stereotypical adjectives and show higher self-concept. Boys preferred to perform male oriented tasks that were related to outgoing activities where as females perform in door activities mostly related to household chores and taking care of the family members. On the whole girls had lower self-concept then boys. It is concluded that parent's and society's expectations in terms of gender related tasks have a strong impact on the kind of self- concept the youngsters develop.

\section{References}

Ansari, L. A., Farooqi, G., Khan, S., \& Naheed, G. (1982). Urdu Acijective Checklist (UACL).Unpublished manscript. National Institute of psychology, Quaid-i-Azam university Islamabad, Pakistan.

Archer, J., \& McDonald, M. (1990). Gender roles and Adolescents girls. Leisure's Studies, 9,224-240.

Asci, F. H. (2002). An investigation of age and gender differences in physical self concept among Turkish late adolescence. Retrieved November 20, 2003 from httpll www.findartical.com/cf/ _ O/m22481 $146.37 / \mathrm{pl} /$ article.html

Barber B. K. (2002). Intrusive parenting : How psychological control affects children and adolescents. USA: American Psychological Association. Retrieved November 12, 2003 from http://www.mentalhelp.net/psyhelp/chapI4htm.file/ self concept theories.htm.

Bem, S. L. (1974). The measurement of psychological androgyny. Journal of Consulting and Clinical Psychology, 42, $155-162$.

Carter, D. C. (1987). Current conceptions of sex des and sex typing: Theory and research. New York: Praeger

Carter, R. S., \& Wojtkiewicz, R. A. (2000) Parental involvement with adolescents' education: do daughters or sons get more help. Retrieved on 30 October, 2003

Eccles, J. S. (1989). Self-concepts, domain values, land self-esteem: relations and changes at early adolescence. Journal of Personality, 57(2),283-310. 
Fagot, B. 1., Hort B. E., \& Leinbach M. D., \& Strayer, J. (1997). Qualities underlying the definitions of gender contributors. Sex Roles: A Journal of Research. 37(1-2) 1-6. Retrieved on 23 Octoper, 2003 from www.questia.com

Fernandaz, T. M. (2001) Gender role attitudes and marital coping in couples. Unpublished Msc. research report National Institute of Psychology Quaid-i-Azam University, Islamabad.

Garton, A. \& Pratt, C. (1998). Learning to be literate: The development of spoken and written language (2nd ed.). New York: Blackwell

Green, E., Hebron, S., \& Woodward, E. (1990). Women's leisure: What leisure? Basingstoke, Hampshire: Macmillan.

Hodge, C.A., Jakson, L.A. \& Ingram, J.M. (1994). Gender and Self concept: reexamination of stereotypic differences and the role of Gender Attitudes. Sex roles: A Journal of research. 30 (9-10, 615-62. Retrieved on 21 October, 2013 from www.questia.com

Horrocks J. E. (1976). The psychology of adolescence (4 ${ }^{\text {th }}$ ed.) Boston: Houghton Mifflin Company.

Jacklin, C. N. (1989). Female and male issue of gender. American psychologists, 44(2), 127-133.

Jung, C. G. (1933). Modern man in search of a soul. New York: Harcourt Brace Jovanovich.

Jung, C. G. (1959). The arche type and the collective upconscious. New Jersey: Prentice Hall.

Kohlberg, L. (1973). The Claim to Moral Adequacy of a Highest Stage of Moral Judgment. Journal of Philosophy, 70(18), 630-646.

Lefrancoise, G. R. (1981). Adolescents ( $2^{\text {nd }}$ ed) California: Wordsworth. London: MacMillian.

Lorber, Judith. 1994. Paradoxes of gender. New Haven, CT: Yale University Press

Maccoby, E. E., \& Jacklin, C. N. (1974). The psychology of sex differences. Stanford, CA: Stanford University. 
Maccoby, E. E., \& Jacklin, C. N. (1974). The psychology of sex differences. Stanford, CA: Stanford University.

Pervez, S. (1996). Factors responsible for sex- typing. In I. N. Hassan (Ed.), Psychology of women (pp. 181-204). Islamabad: Allama Iqbal Open University.

Raymore, L. A., Godbey, G., \& Crawford, D. W. (1994). Self-esteem, gender, and socioeconomic status: Their relationship to perceptions of constraint on leisure among adolescents. Journal of Leisure Research, 26(2), 99-118.

Raymore, L. A., Goodbye, G. C., \& Crawford, D.W. (1994). Self-esteem, gender, and socioeconomic status: Their relation to perceptions of constraint on leisure among adolescents. Journal of Leisure Research, 26, 99-118.

Rogers, C. R. (1961). On Becoming a person, Boston: Houghton Mifflin Co.

Rogers, D. (1972). The psychology of adolescence ( $2^{\text {nd }}$ ed.) USA: Meredith Corporation

Rogers,C.R.(1977). Carl Rogers on personal power .NewYork: Delacorte.

Ruble, D. N. (1988). Sex role development. In M. H. Barnstein \& M. E. Lamb (eds.) Developmental psychology:An advanced textbook, 2nd ed. Hillsdale, NJ: Erlbaum.

Weitz. S. (1977) Sex roles: Biological, psychological, and social foundation. New York: Methuen.

Dr. Nazia Iqbal is Assistant Professor in the Department of Psychology, International Islamic University Islamabad.

Dr. Nighat Gillani is Associate Professor in the National Institute of Psychology, Quaidi-Azam University.

Dr. Anila Kamal is Professor in the National Institute of Psychology, Quaid-i-Azam University. 